\title{
Pengaruh Metode Drill dalam Supervisi Klinis terhadap Spiritual Care Perawat
}

\author{
Nunung Rachmawati ${ }^{1}$, Luky Dwiantoro ${ }^{2}$, Bambang Edi Warsito ${ }^{2}$
}

\begin{abstract}
${ }^{1}$ Mahasiswa Magister Manajemen Keperawatan Universitas Diponegoro, Indonesia ${ }^{2}$ Departemen Keperawatan Fakultas Kedokteran Universitas Diponegoro, Indonesia Jalan Prof H. Soedarto SH, Tembalang, Semarang, Indonesia Email: adan_wafa2000@yahoo.com
\end{abstract}

\begin{abstract}
Abstrak
Pelayanan keperawatan holistik didasarkan pada konsep bahwa manusia sakit tidak hanya secara fisik yang hanya disembuhkan dengan pemberian obat, tetapi juga memperhatikan aspek yang lainnya yaitu mental dimana pasien membutuhkan motivasi dan semangat untuk menghadapi penyakit, sosial dimana pasien ingin bertemu dan berkumpul dengan keluarga/teman dan spiritual dimana pasien ingin berdoa dan didoakan untuk kesembuhan. Spiritual care merupakan salah satu bagian yang penting dari keseluruhan perawatan yang diberikan untuk meningkatkan kualitas kehidupan pasien. Peran perawat saat ini lebih banyak terlibat pada tindakan pengobatan (fisik). Metode yang tepat dalam supervisi klinis diperlukan agar perawatan spiritual menjadi hal yang biasa dilakukan seperti halnya perawatan fisik, salah satunya menggunakan metode drill. Penelitian ini bertujuan untuk menganalisis pengaruh metode drill dalam supervisi klinis ketua tim terhadap pelaksanaan spiritual care perawat. Metode penelitian yang digunakan adalah quasy experiment dengan rancangan penelitian pretest- posttest with control group design. Populasi pada penelitian ini adalah perawat di ruang rawat inap RS PKU Muhammadiyah Yogyakarta dan Gamping. Teknik pengambilan sampel dengan menggunakan consecutive sampling, yaitu masing-masing 16 perawat pada kelompok intervensi dan kontrol. Pelaksanaan spiritual care dilihat dengan menggunakan lembar observasi mengacu pada label Nursing Interventions Classivication, spiritual care diobservasi sebelum dan sesudah penerapan metode drill dalam supervisi klinis. Data dianalisis dengan uji paired t test. Hasil penelitian menunjukkan rata-rata spiritual care perawat sebelum diterapkan metode drill 6,56 pada kelompok intervensi dan 6,13 pada kelompok kontrol, setelah diterapkan metode drill 17,44 pada kelompok intervensi dan 6,50 pada kelompok kontrol. Hasil uji statistik menunjukkan terdapat perbedaan yang signifikan pada spiritual care perawat sebelum dan sesudah penerapan metode drill pada kelompok intervensi. Disarankan bagi pihak rumah sakit untuk meningkatkan pelaksanaan supervisi klinis kepada perawat terkait keterampilan perawatan non fisik menggunakan metode drill.
\end{abstract}

Kata Kunci: metode drill, perawatan spiritual, perawat

\section{The Effect of Drill Method in Clinical Supervision for Inhance of Spiritual Care}

\begin{abstract}
The holistic nursing service is based on the concept that humans are sick not only physically that cured by drug delivery, but also pay attention to other aspects of mental where the patient needs motivation and spirit to cope with illness, social where the patient wants to meet and gather with family/friends and spiritual where the patient wants to pray and pray for healing. Spiritual care is an important part of the overall care provided to improve the quality of life of patients. The role of nurses is now more involved on treatment measures. Proper methods in clinical supervision are necessary for the implementation of spiritual care to be as important as physical care, one of them using drill method. This study aims to analyze the influence of drill methods in the team leader's clinical supervision on the implementation of nurses spiritual care. The research method used is quasy experiment with pretest-posttest research design with control group design. The population of nurse research in inpatient room of PKU Muhammadiyah Yogyakarta and PKU Muhammadiyah Gamping Hospital. A
\end{abstract}


total of 32 nurses were taken as samples through consecutive sampling technique. To see the implementation of spiritual care used observation sheet refers to the label Nursing Interventions Classification, spiritual care is observed before and after the application of drill methods in clinical supervision. Data were analyzed by paired t-test. The results showed the average of nurses' spiritual care before the drill method applied to the intervention group was 6,56 and 6,13 in the control group, after drill method applied in the intervention group was 17,44 and 6,50 in the control group. The results of statistical tests showed that there was a significant difference in nurse's spiritual care before and after the application of drill methods in the intervention group. It is recommended for the hospital to improve the implementation of clinical supervision to the nurses related to non-physical skills using drill method.

Keywords: drill method, nurse, spiritual care

Info Artikel:

Artikel dikirim pada 23 Mei 2017

Artikel direvisi pada 28 Agustus 2017

Artikel diterima pada 20 September 2017

DOI: http://dx.doi.org/10.21927/jnki.2017.5(2).115-122

\section{PENDAHULUAN}

World Health Organization (WHO) menekankan pentingnya kesejahteraan fisik, psikologi, sosial dan spiritual bukan hanya berfokus pada penyakit. Spiritual care dianggap sebagai bagian yang penting dari keseluruhan perawatan yang diberikan untuk meningkatkan kualitas kehidupan pasien dan keluarganya. Menggunakan perawatan spiritual dan agama sebagai sumbernya memberikan pasien dan keluarga kekuatan untuk menghadapi penyakitnya, akan tetapi perawat sering tidak memberikannya (1).

Perawat kurang memperhatikan aspek spiritual dalam perawatan karena perawat kurang memahami tentang aspek spiritual dan manfaatnya terhadap penyembuhan penyakit pasien dan kesehatan pasien (2). Banyak perawat menyetujui bahwa perawatan spiritual merupakan hal yang penting bagi pasien tetapi sebagian besar tidak mampu untuk memberikan perawatan spiritual secara tepat kepada pasien mereka (3).

Penelitian yang dilakukan di Amerika Serikat menunjukkan bahwa $94 \%$ dari pasien yang berkunjung ke rumah sakit meyakini bahwa kesehatan spiritual sama pentingnya dengan kesehatan fisik (4). Penelitian menunjukkan bahwa memberikan perawatan spiritual kepada pasien dapat membantu pasien meningkatnya kenyamanan fisik, menurunkan level kecemasan, dan meningkatkan harapan pasien untuk masa depannya. Selain itu, perawatan spiritual sebagai sumber koping pasien (sumber kekuatan yang sangat diperlukan untuk dapat menerima keadaan sakitnya khususnya jika penyakit tersebut membutuhkan waktu penyembuhan yang lama), meningkatkan manajemen nyeri pasien, memperbaiki hasil pembedahan, melindungi pasien dari depresi, dan meminimalkan kesempatan pasien di dalam penyalahgunaan obat terlarang dan perilaku bunuh diri (5).

Peran perawat saat ini lebih banyak terlibat dan memusatkan diri pada tindakan pengobatan (cure) seperti menetapkan diagnosa penyakit dan pemberian obat (6). Hal serupa juga dikemukakan bahwa dalam memberikan asuhan keperawatan, perawat cenderung lebih memperhatikan aspek pengobatan (7). Hasil wawancara yang dilakukan pada lima perawat pelaksana di ruang rawat inap RS PKU Muhammadiyah Yogyakarta didapatkan bahwa $80 \%$ perawat mengatakan lebih banyak melakukan perawatan fisik ke pasien daripada melakukan perawatan spiritual, sedangkan $20 \%$ mengatakan melakukan perawatan spiritual bersamaan dengan melakukan perawatan fisik.

Metode yang tepat dalam supervisi klinis diperlukan agar pelaksanaan perawatan spiritual tetap diberikan kepada pasien dan menjadi hal yang sama pentingnya dengan perawatan fisik. Metode drill adalah suatu metode dimana seseorang melaksanakan kegiatan latihan agar memiliki ketangkasan atau keterampilan yang lebih tinggi. Metode ini merupakan suatu cara yang baik untuk menanamkan kebiasaan-kebiasaan tertentu (8). Berdasarkan fenomena tersebut, maka tujuan penelitian ini adalah untuk menganalisis pengaruh metode drill dalam supervisi klinis ketua tim terhadap pelaksanaan spiritual care perawat di RS PKU Muhammadiyah Yogyakarta. 


\section{BAHAN DAN METODE}

Rancangan penelitian ini menggunakan quasi eksperimen dengan kelompok kontrol, yaitu pretest posttest with control group design. Penelitian dilakukan di dua rumah sakit swasta yaitu RS PKU Muhammadiyah Yogyakarta sebagai tempat intervensi dan RS PKU Muhammadiyah Gamping sebagai tempat kontrol. Penelitian dilakukan pada bulan Maret sampai April 2017. Responden dalam penelitian ini terdiri dari 32 orang perawat yang dibagi menjadi dua kelompok, dimana masing-masing kelompok terdiri dari 16 orang perawat. Adapun kriteria inklusi yang ditetapkan sebagai berikut minimal pendidikan diploma keperawatan dan perawat pelaksana di ruang rawat inap.

Alat yang digunakan untuk mengukur spiritual care adalah lembar observasi yang dikembangkan peneliti dengan mengacu pada label Nursing Interventions Classivication. Lembar observasi terdiri dari 25 item dimana setiap item terdiri dari dua pilihan yaitu 0 (tidak dilakukan) dan 1 (dilakukan). Lembar observasi ini telah dilakukan uji validitas berdasarkan pendapat tiga pakar yang memiliki pengetahuan ataupun kemampuan luas dalam bidang keperawatan holistik dengan menekankan pada perawatan spiritual baik dari institusi pendidikan maupun dari rumah sakit (klinis) (judgement validity) menggunakan index of content validity dan telah dilakukan uji reliabilitas dengan menggunakan uji Kappa yang melibatkan 10 responden dengan tujuan untuk menyamakan persepsi antara peneliti dengan enumerator. Hasil judgement validity menunjukkan dari 40 item pernyataan hanya terdapat 15 item yang tidak relevan sehingga didapatkan 25 item yang relevan. Hasil uji reliabilitas yang melibatkan 10 responden dengan menggunakan uji Kappa semua hasil menunjukkan lebih dari 0,600 sehingga menunjukkan tidak ada perbedaan persepsi antara peneliti dengan enumerator terkait dengan pelaksanaan spiritual care perawat pelaksana.

Sebelum intervensi metode drill diberikan oleh ketua tim kepada perawat pelaksana, peneliti melakukan observasi awal terkait pelaksanaan spiritual care perawat pelaksana. Setelah data terkait pelaksanaan spiritual care perawat pelaksana diperoleh intervensi metode drill diberikan oleh ketua tim kepada perawat pelaksana untuk meningkatkan pelaksanaan spiritual care dimana ketua tim telah diberikan pelatihan metode drill selama satu hari dilanjutkan dengan pendampingan selama enam hari dan mandiri selama satu minggu.
Metode drill yang digunakan ketua tim dalam pelaksanaan supervisi klinisnya dapat digunakan secara kelompok atau individu kepada perawat pelaksana. Dalam penelitian ini ketua tim melakukan drill keterampilan perawatan spiritual kepada perawat pelaksana secara individu. Sebelum ketua tim melakukan drill perawatan spiritual kepada perawat pelaksana, ketua tim menentukan keterampilan perawatan spiritual apa yang akan dilatihkan, menyiapkan materi perawatan spiritual yang akan disampaikan dan melakukan kontrak waktu dengan perawat pelaksana. Drill perawatan spiritual diawali dengan penyampaian materi secara singkat dan pemberian contoh pelaksanaan perawatan spiritual oleh ketua tim, kemudian perawat pelaksana diberi kesempatan untuk berlatih keterampilan perawatan spiritual ke pasien dengan didampingi oleh ketua tim. Latihan berulang (drill) perawatan spiritual diberikan oleh ketua tim kepada perawat pelaksana dengan pasien yang berbeda. Ketua tim memberikan bimbingan terkait pelaksanaan perawatan spiritual yang telah dilakukan oleh perawat pelaksana, memberikan motivasi dan semangat kepada perawat pelaksana. Evaluasi dilakukan oleh ketua tim di akhir pelaksanaan untuk mengetahui pencapaian pelaksanaan perawatan spiritual dan kesulitan yang dihadapai oleh perawat pelaksana sebagai perbaikan untuk drill selanjutnya. Setelah ketua tim melakukan drill perawatan spiritual kepada perawat pelaksana secara mandiri selama satu minggu, kemudian peneliti melakukan observasi lagi terkait pelaksanaan perawatan spiritual yang dilakukan oleh perawat pelaksana.

Analisis data dilakukan peneliti untuk menjawab tujuan yang ingin dicapai dalam penelitian ini, yaitu analisis univariat dan bivariat. Analisis univariat untuk menjelaskan atau mendiskripsikan karakteristik perawat (usia, jenis kelamin, pendidikan, masa kerja, dan status), mengetahui pelaksanaan spiritual care perawat pelaksana sebelum drill dalam supervisi klinis diterapkan, dan mengetahui pelaksanaan spiritual care perawat pelaksana setelah drill dalam supervisi klinis diterapkan. Analisis bivariat dilakukan untuk mengetahui pengaruh metode drill dalam supervisi klinis ketua tim terhadap pelaksanaan spiritual care perawat pelaksana, analisis yang digunakan uji parametrik dengan paired t-test.

\section{HASIL DAN BAHASAN}

Karakteristik responden pada penelitian ini dibedakan atas usia, masa kerja, pendidikan, jenis kelamin, status pernikahan dan riwayat hospitalisasi 
yang dapat dilihat pada Tabel 1. Berdasarkan tabel tersebut terlihat bahwa rata-rata usia responden pada kelompok intervensi adalah 28,75 tahun dan pada kelompok kontrol 26,63 tahun. Masa kerja rata-rata responden pada kelompok intervensi adalah 5,0256 tahun dan pada kelompok kontrol 2,25 tahun. Pendidikan pada kelompok intervensi dan kontrol sebagian besar Diploma Keperawatan yaitu sebanyak 14 orang $(87,5 \%)$ pada kelompok intervensi dan 9 orang $(56,3 \%)$ pada kelompok kontrol. Jenis kelamin pada kelompok intervensi dan kontrol sebagian besar perempuan yaitu sebanyak 10 orang $(62,5 \%)$ pada kelompok intervensi dan 14 orang $(87,5 \%)$ pada kelompok kontrol. Status pernikahan pada kelompok intervensi sebagian besar sudah menikah yaitu sebanyak 9 orang $(56,3 \%)$, sedangkan pada kelompok kontrol sebagian besar belum menikah yaitu sebanyak 10 orang (62,5\%). Riwayat hospitalisasi pada kelompok intervensi sebagian besar pernah dirawat di rumah sakit yaitu sebanyak 11 orang $(68,8 \%)$, sedangkan pada kelompok kontrol sebagian besar belum pernah dirawat di rumah sakit yaitu sebanyak 10 orang (62,5\%).

Pelaksanaan spiritual care perawat pelaksana pada kelompok intervensi dan kontrol masih kurang meskipun sebagian besar perawat dengan jenis kelamin perempuan yaitu $62,6 \%$ pada kelompok intervensi dan $87,5 \%$ pada kelompok kontrol. Hal ini sejalan dengan hasil penelitian Chan yang menyatakan bahwa jenis kelamin tidak berpengaruh secara signifikan terhadap kecenderungan untuk mempraktekkan perawatan spiritual (9). Namun hal ini tidak sejalan dengan hasil penelitian Melhem et al. yang menyatakan bahwa perawat perempuan dilaporkan mempunyai level persepsi spiritualitas dan perawatan spiritual yang lebih tinggi dibandingkan perawat laki-laki (5). Perawat perempuan mempunyai kemampuan yang lebih baik dalam berbagi emosi dan perasaan dengan pasien bila dibandingkan dengan perawat laki-laki.

Pelaksanaan spiritual care perawat pelaksana pada kelompok intervensi dan kontrol juga masih kurang meskipun masa kerja perawat pada kelompok intervensi lebih lama daripada perawat pada kelompok kontrol. Hal ini sejalan dengan hasil penelitian Chan dan Melhem yang menyatakan bahwa lamanya pengalaman klinik perawat tidak berpengaruh secara signifikan terhadap kecenderungan untuk mempraktekkan perawatan spiritual $(5,9)$.

Berdasarkan Tabel 2 memperlihatkan bahwa nilai rata-rata spiritual care perawat pelaksana sebelum diterapkan metode drill pada kelompok intervensi adalah 6,56. Nilai standar deviasi 2,279 dengan nilai minimum 4 dan nilai maksimum 12. Nilai rata-rata spiritual care perawat pelaksana sesudah diterapkan metode drill adalah 17,44 . Nilai standar deviasi 3,502 dengan nilai minimum 11 serta nilai maksimum 24. Tabel 2 juga memperlihatkan bahwa nilai rata-rata spiritual care perawat pelaksana sebelum pada kelompok kontrol adalah 6,13 . Nilai standar deviasi 1,258 dengan nilai minimum 4 dan nilai maksimum 8 . Nilai rata-rata spiritual care

Tabel 1. Karakteristik Responden di RS PKU Muhammadiyah Yogyakarta dan Gamping Tahun 2017

\begin{tabular}{|c|c|c|c|}
\hline \multirow[b]{2}{*}{ Karakteristik } & \multicolumn{2}{|c|}{ Kelompok } & \multirow[b]{2}{*}{ p-value } \\
\hline & $\begin{array}{c}\text { Intervensi } \\
(n=16)\end{array}$ & $\begin{array}{c}\text { Kontrol } \\
(n=16)\end{array}$ & \\
\hline \multicolumn{4}{|l|}{ Usia } \\
\hline Mean & 28,75 & 26,63 & 0,088 \\
\hline Min-Max & $23-48$ & $24-32$ & \\
\hline \multicolumn{4}{|l|}{ Masa kerja } \\
\hline Mean & 5,0256 & 2,25 & 0,000 \\
\hline Min-Max & $0,16-17,5$ & 1,4 & \\
\hline \multicolumn{4}{|l|}{ Pendidikan, $\Sigma(\%)$} \\
\hline Diploma & $14(87,5 \%)$ & $9(56,3 \%)$ & 0,000 \\
\hline Ners & $2(12,5 \%)$ & $7(43,8 \%)$ & \\
\hline \multicolumn{4}{|l|}{ Jenis Kelamin, $\Sigma(\%)$} \\
\hline Laki-laki & $6(37,5 \%)$ & $2(12,5 \%)$ & 0,001 \\
\hline Perempuan & $10(62,5 \%)$ & $14(87,5 \%)$ & \\
\hline \multicolumn{4}{|l|}{ Status Pernikahan, $\Sigma(\%)$} \\
\hline Menikah & $9(56,3 \%)$ & $6(37,5 \%)$ & 0,510 \\
\hline Belum Menikah & $7(43,8 \%)$ & $10(62,5 \%)$ & \\
\hline \multicolumn{4}{|c|}{ Riwayat Hospitalisasi, $\Sigma(\%)$} \\
\hline Pernah & $11(6,8 \%)$ & $6(37,5 \%)$ & 0,481 \\
\hline Belum Pernah & $5(31,3 \%)$ & $10(62,5 \%)$ & \\
\hline
\end{tabular}


Tabel 2. Gambaran Spiritual Care Perawat Pelaksana Sebelum dan Sesudah Diterapkan Metode Drill pada Kelompok Intervensi di RS PKU Muhammadiyah Yogyakarta dan Kelompok Kontrol di RS PKU Muhammadiyah Gamping Tahun 2017

\begin{tabular}{lccccc}
\hline Kelompok & $\begin{array}{c}\text { Penerapan } \\
\text { metode drill }\end{array}$ & Mean & SD & Min-Maks & $\begin{array}{c}\text { 95\% Cl } \\
\text { (Upper-Lower) }\end{array}$ \\
\hline Intervensi & Sebelum & 6,56 & 2,279 & $4-12$ & $7,78-5,35$ \\
& Sesudah & 17,44 & 3,502 & $11-24$ & $19,11-15,27$ \\
\multirow{2}{*}{ Kontrol } & Sebelum & 6,13 & 1,258 & $4-8$ & $6,80-5,45$ \\
& Sesudah & 6,50 & 0,894 & $5-8$ & $6,98-6,02$ \\
\hline
\end{tabular}

perawat pelaksana sesudah pada kelompok kontrol adalah 6,50. Nilai standar deviasi 0,894 dengan nilai minimum 5 serta nilai maksimum 8 .

Berdasarkan hasil observasi langsung terkait pelaksanaan spiritual care perawat pelaksana pada kelompok intervensi sebelum perlakuan menunjukkan bahwa perawat belum melakukan beberapa perawatan spiritual kepada pasien, misalnya tidak menanyakan apakah pasien dan keluarga membutuhkan pemuka agama, tidak mendorong keluarga dan atau kerabat mendoakan pasien, serta tidak meminta keluarga dan atau kerabat untuk mengingatkan pasien ibadah. Hasil penelitian tersebut menunjukkan bahwa pelaksanaan spiritual care perawat masih kurang. Hasil tersebut sesuai dengan penelitian Utami \& Supratman yang menyatakan bahwa perawat kurang memperhatikan aspek spiritual dalam perawatan karena perawat kurang memahami tentang aspek spiritual dan manfaatnya terhadap penyembuhan penyakit pasien dan kesehatan pasien (2). Peran perawat dalam pemenuhan kebutuhan spiritual pasien belum terpenuhi dengan optimal. Meskipun banyak perawat yang menyetujui bahwa perawatan spiritual adalah tanggungjawab perawat, terdapat perbedaan antara keyakinan tersebut dengan kenyataan dalam memberikan perawatan spiritual (1). Hal ini didukung oleh adanya riset Utami dan Supratman yang menunjukkan bahwa perawat merasa tidak mampu memberikan perawatan spiritual kepada pasien dengan alasan perawat memandang pemenuhan kebutuhan spiritual pasien bukan tanggungjawabnya melainkan tanggungjawab keluarga dan tokoh agama (2).

Hasil observasi secara langsung pada kelompok intervensi dan kelompok kontrol sebelum perlakuan menunjukkan belum diterapkannya fungsi supervisi klinis dengan baik dan efektif, misalnya supervisor ruangan hanya melakukan supervisi saat melaksanakan timbang terima dari satu shift ke shift yang berikutnya, pelaksanaan supervisi klinis belum dilaksanakan secara kontinu, belum terjadwal, dan tidak terdokumentasi sehingga supervisi klinis yang dilakukan belum dapat memberikan informasi yang objektif terkait pelaksanaan sesuai dengan standar yang berlaku. Dampak dari supervisi klinis yang belum optimal terhadap pelaksanaan perawatan spiritual adalah semakin terlantarnya perawatan spiritual dalam praktek keperawatan sehari-hari dan sedikitnya perhatian yang diberikan pada kebutuhan spiritual pasien. Hasil wawancara yang dilakukan pada lima perawat pelaksana di ruang rawat inap RS PKU Muhammadiyah Yogyakarta didapatkan bahwa $80 \%$ perawat mengatakan lebih banyak melakukan perawatan fisik ke pasien daripada melakukan perawatan spiritual.

Pelaksanaan spiritual care perawat pelaksana setelah supervisi klinis dengan metode drill mengalami peningkatan pada kelompok intervensi yaitu nilai rerata 17,44 begitu juga pada kelompok kontrol yaitu 6,50 . Perlakuan yang dilakukan pada kelompok intervensi dalam penelitian, yaitu dengan memberikan latihan berulang (metode drill) dalam supervisi klinis oleh ketua tim terhadap pelaksanaan spiritual care perawat pelaksana sedangkan pada kelompok kontrol tidak dilakukan intervensi tersebut. Hasil penelitian menunjukan bahwa supervisi klinis dengan metode drill (latihan berulang) lebih signifikan dalam meningkatkan pelaksanaan spiritual care perawat pelaksana.

Sejalan dengan hasil penelitian Sukremi, Agung dan Ambara yang menunjukkan bahwa latihan yang diulang-ulang dapat meningkatkan perkembangan kognitif, keterampilan, melatih kemandirian dan cara yang baik untuk menanamkan kebiasaan-kebiasaaan tertentu (8). Pelaksanaan perawatan spiritual perawat pelaksana meningkat dikarenakan latihan berulang yang dilakukan oleh ketua tim dalam supervisi klinis. Sesuai dengan teori Lewin bahwa dalam proses berubah sampai mencapai tahap pembekuan dimana perawat konsisten dalam melakukan tindakan dibutuhkan bimbingan dan pengarahan secara terus menerus sesuai dengan konsep supervisi $(10,11)$. 
Hasil analisis juga menunjukkan bahwa pada kelompok kontrol yang tidak dilakukan intervensi penerapan supervisi klinis dengan metode drill terlihat tidak ada perbedaan bermakna antara sebelum dan sesudah perlakuan. Artinya hasil penelitian ini menunjukkan bahwa penerapan supervisi klinis dengan metode drill oleh ketua tim terbukti efektif dalam meningkatkan pelaksanaan perawatan spiritual perawat pelaksana. Hasil analisis pada kelompok kontrol yang diukur saat bersamaan sesudah kelompok intervensi menjalani perlakuan menunjukkan bahwa pelaksanaan perawatan spiritual memiliki rentang nilai 5-8 dengan nilai rata-rata 6,50. Hal ini menunjukkan tidak terlalu signifikannya perubahan yang terjadi jika dibandingkan dengan data hasil pengukuran awal karena hanya mengalami peningkatan sebesar 0,37 dari nilai awal.

Perubahan terjadi tidak hanya pada kelompok intervensi akan tetapi juga terjadi pada kelompok kontrol, walaupun tidak terlalu bermakna. Hal ini disebabkan karena jumlah perawat pelaksana dengan pendidikan diploma dan ners tidak berbeda terlau jauh. Dimana perawat dengan pendidikan diploma berjumlah sembilan orang $(56,3 \%)$ dan perawat dengan pendidikan ners berjumlah tujuh orang $(43,8 \%)$. Hasil penelitian Wong menemukan bahwa perawat dengan tingkat pendidikan sarjana lebih baik dalam memberikan spiritual care, oleh karena itu pendidikan mempunyai pengaruh yang positif terhadap pemberian spiritual care oleh perawat kepada pasien (12). Perawat dengan pendidikan yang semakin baik akan melakukan praktik keperawatan yang efektif dan efisien yang selanjutnya akan menghasilkan pelayanan kesehatan yang bermutu tinggi. Tingkat pendidikan yang cukup akan memberikan kontribusi terhadap praktik keperawatan.

Perubahan tidak terlalu signifikan pada kelompok kontrol juga disebabkan karena perawat bekerja di rumah sakit swasta yaitu RS PKU Muhammadiyah. Hasil penelitian Melhem et al. menyatakan bahwa perawat yang bekerja di rumah sakit swasta dilaporkan memiliki level persepsi spiritualitas dan perawatan spiritual yang lebih tinggi dibandingkan dengan perawat yang bekerja di rumah sakit pemerintah (5). Hal inilah yang menjadi penyebab terdapat perubahan pada pelaksanaan perawatan spiritual yang tidak terlalu bermakna walaupun tidak diberikan intervensi berupa metode drill yang dilakukan dalam supervisi klinis ketua tim.
Tabel 3. Pengaruh Metode Drill terhadap Pelaksanaan Spiritual Care Perawat Pelaksana pada Kelompok Intervensi di RS PKU Muhammadiyah Yogyakarta dan Kelompok Kontrol di RS PKU Muhammadiyah Gamping Tahun 2017

\begin{tabular}{|c|c|c|c|c|}
\hline Kelompok & Variabel & Mean & Selisih & p-value \\
\hline \multirow[t]{3}{*}{ Intervensi } & $\begin{array}{l}\text { Spiritual } \\
\text { care perawat } \\
\text { pelaksana }\end{array}$ & & & \\
\hline & Sebelum & 6,56 & 10,875 & 0,000 \\
\hline & Sesudah & 17,44 & & \\
\hline \multirow[t]{3}{*}{ Kontrol } & $\begin{array}{l}\text { Spiritual } \\
\text { care perawat } \\
\text { pelaksana }\end{array}$ & & & \\
\hline & Sebelum & 6,13 & 0,37 & 0,232 \\
\hline & Sesudah & 6,50 & & \\
\hline
\end{tabular}

Berdasarkan Tabel 3 tersebut memperlihatkan bahwa nilai rata rata spiritual care perawat pelaksana pada kelompok intervensi sebelum penerapan metode drill adalah 6,56 sedangkan sesudah diterapkan metode drill nilai rata-rata mengalami peningkatan menjadi 17,44 . Hasil ini menunjukkan terjadinya peningkatan sebesar 10,875. Dari hasil uji statistik diketahui $p$-value $=0,000$ dan $\alpha=0,05$, nilai $p$-value $<\alpha$ yang berarti ada perbedaan nilai rata-rata sebelum dan sesudah diterapkannya metode drill dengan kata lain, penerapan metode drill berpengaruh terhadap spiritual care perawat pelaksana. Nilai rata-rata spiritual care perawat pelaksana pada kelompok kontrol sebelum didapatkan 6,13 dan untuk nilai rata-rata sesudah adalah 6,50 . Hal ini menunjukkan terjadi peningkatan spiritual care perawat pelaksana sebesar 0,37 . Berdasarkan hasil uji statistik nilai $p$-value $=0,232$ yang berarti $p$-value $>0,05 \mathrm{Ho}$ diterima sehingga tidak ada perbedaan yang signifikan nilai rata-rata spiritual care perawat pelaksana sebelum dengan setelah pada kelompok kontrol.

Hasil analisis menunjukkan bahwa pada kelompok intervensi terjadi peningkatan nilai ratarata 10,875 , sedangkan pada kelompok kontrol peningkatan nilai rata-rata hanya 0,37 . Hal ini membuktikan ada pengaruh supervisi klinis dengan metode drill yang dilakukan ketua tim terhadap pelaksanaan perawatan spiritual perawat pelaksana di RS PKU Muhammadiyah Yogyakarta $(p=0,000)$.

Perbedaan hasil analisis antara kelompok intervensi dan kelompok kontrol menunjukkan bahwa kelompok intervensi dan kelompok kontrol memberikan respon yang berbeda berdasarkan ada atau tidak adanya stimulus berupa perlakuan supervisi klinis dengan metode drill oleh ketua tim kepada 
perawat pelaksana. Supervisi klinis merupakan proses yang dapat memacu anggota unit kerja untuk berkontribusi secara aktif dan positif agar tujuan tercapai. Supervisi klinis yang dilakukan dengan baik berdampak positif bagi kualitas perawatan. Penelitian Widiyanto, Hariyati \& Handiyani menyimpulkan bahwa supervisi klinis dianggap efektif untuk membantu meningkatkan perawatan pasien (13). Konsep perawatan spiritual telah dikaitkan dengan kualitas perawatan interpersonal dalam hal ekspresi cinta dan welas asih terhadap pasien (9). Berdasarkan hasil penelitian maka dapat diketahui bahwa penerapan metode drill dalam supervisi klinis yang dilakukan oleh ketua tim terhadap perawat pelaksana dapat meningkatkan pelaksanaan perawatan spiritual perawat pelaksana di RS PKU Muhammadiyah Yogyakarta.

Penelitian Susilowati, Santoso dan Hamidi menyatakan bahwa penerapan metode drill dapat meningkatkan antusias, semangat, disiplin dan tanggungjawab (14). Penelitian Sukremi et al. menyatakan bahwa penerapan metode drill dapat meningkatkan kognitif, ketrampilan dan melatih kemandirian (8). Kelebihan dari implementasi supervisi klinis dengan metode drill diantaranya adalah dalam waktu yang tidak lama perawat pelaksana dapat memperoleh pengetahuan dan keterampilan yang diperlukan, perawat pelaksana memperoleh pengetahuan praktis, mahir dan lancar, serta menumbuhkan kebiasaan, disiplin diri dan kemandirian. Pelaksanaan spiritual care meningkat melalui kesempatan latihan berulang (metode drill) yang diberikan oleh ketua tim kepada perawat pelaksana sehingga materi yang diberikan kepada perawat pelaksana lebih melekat dalam pikiran yang pada akhirnya membentuk kebiasaaan perawat pelaksana. Dengan demikian terbentuklah ketrampilan perawatan spiritual yang setiap saat siap untuk digunakan oleh perawat pelaksana.

Metode drill merupakan suatu metode yang diambil peneliti dari metode pembelajaran yang biasa digunakan pendidik kepada anak didiknya untuk membentuk sebuah kebiasaan. Istilah drill digunakan untuk latihan dengan mengulangi materi yang dipelajari sampai dikuasai. Latihan merupakan komponen pembelajaran yang sangat penting. Dalam penelitian ini metode drill digunakan ketua tim dalam supervisi klinis dimana perawat pelaksana sering diajak melakukan latihan perawatan spiritual ke pasien. Dengan sering latihan perawat pelaksana dapat memperoleh kecakapan motoris, kecakapan mental dan selain itu metode latihan juga dapat membentuk kebiasaan.

\section{SIMPULAN DAN SARAN}

Hasil penelitian didapatkan bahwa spiritual care perawat pelaksana sebelum metode drill diterapkan dalam supervisi klinis ketua tim pada kelompok intervensi rata-rata sebesar 6,56 dan kelompok kontrol rata-rata sebesar 6,13 . Sedangkan spiritual care perawat pelaksana setelah metode drill diterapkan dalam supervisi klinis ketua tim pada kelompok intervensi rata-rata sebesar 17,44 dan kelompok kontrol rata-rata sebesar 6,50. Hasil uji statistik didapatkan bahwa terdapat perbedaan spiritual care perawat sebelum dan sesudah metode drill diterapkan dalam supervisi klinis ketua tim pada kelompok intervensi $(p=0,000)$ dan kelompok kontrol $(p=0,232)$.

Berdasarkan hasil penelitian peneliti memberikan saran kepada manajer keperawatan diharapkan dapat terus melakukan pengembangan keprofesionalan staf perawat dengan menciptakan budaya kerja melalui kegiatan supervisi klinis dengan metode drill, selain itu juga hasil penelitian ini dapat digunakan sebagai dasar untuk penelitian selanjutnya sehingga dalam melakukan penelitian berikutnya diharapkan peneliti melihat keefektifan penerapan metode drill dalam supervisi klinis dalam meningkatkan keterampilan lain dari perawat pelaksana dan peneliti diharapkan tidak terlibat secara langsung dalam proses observasi.

\section{RUJUKAN}

1. Belinda D. A Pilot Study of Nurses' Experience of Giving Spiritual Care [Internet]. Vol. 15, The Qualitative Report. Nova Southeastern University, School of Social and Systematic Studies; 2010 [cited 2017 Sep 19]. Available from: http:// nsuworks.nova.edu/tqr/vol15/iss $4 / 5$

2. Yuni WU, Supratman. Hubungan antara Pengetahuan dengan Sikap Perawat dalam Pemenuhan Kebutuhan Spiritual Pasien di BRSUD Sukoharjo. Ber IImu Keperawatan [Internet]. 2009 Apr 1 [cited 2017 Sep 19];2(2):6974. Available from: http://journals.ums.ac.id/index. php/BIK/article/view/3795

3. Khoiriyati A. Perawatan Spiritual dalam Keperawatan : Sebuah Pendekatan Sistematik. J Mutiara Med [Internet]. 2016 May 31 [cited 2017 
Sep 20];8(1):48-51. Available from: http://journal. umy.ac.id/index.php/mm/article/view/1654

4. Ristianingsih D, Septiwi C, Isma Yuniar. Gambaran Motivasi dan Tindakan Keperawatan dalam Pemenuhan Kebutuhan Spiritual Pasien di Ruang ICU PKU Muhammadiyah Gombong. J IIm Kesehat Keperawatan [Internet]. 2014 [cited 2017 Sep 20];10(2):91-9. Available from: http://download.portalgaruda.org/article.php? article $=414104 \& \mathrm{val}=4792 \&$ title $=$ GAMBARAN MOTIVASI DAN TINDAKAN KEPERAWATAN DALAM PEMENUHAN KEBUTUHAN SPIRITUAL PASIEN DI RUANG ICU PKU MUHAMMADIYAH GOMBONG

5. Melhem GB, Zeilani R, Zaqqout $O$, Aljwad A, Shawagfeh M, Al- Rahim M. Nurses' Perceptions of Spirituality and Spiritual Care Giving : a Comparasion Study Among All Health Care Sectors in Jordan. Indian J Palliat Care [Internet]. 2016;22(1):42. Available from: http://www.jpalliativecare.com/text. asp?2016/22/1/42/173949

6. Suryani M, Mey LCH. Persepsi Pasien Terhadap Caring Perawat di Ruang Rawat Inap Rumah Sakit. J Kesehat Masy Nas [Internet]. 2013 [cited 2017 Sep 20];8(3):104-8. Available from: https:// media.neliti.com/media/publications/39802ID-persepsi-pasien-terhadap-perilaku-caringperawat-di-ruang-rawat-inap-rumah-sakit.pdf

7. Syaiful Y, Wibawa S. Pengetahuan dan Sikap Perawat Memenuhi Kebutuhan Spiritual Pasien Kritis dengan Implementasi Keperawatan. Journals Ners Community [Internet]. 2014 Jun 5 [cited 2017 Sep 20];5(1). Available from: http:// journal.unigres.ac.id/index.php/JNC/article/ view/73
8. Sukremi K, Agung A, Ambara D. Penerapan Metode Drill Berbantuan Media Tangram untuk Meningkatkan Perkembangan Kognitif Anak Kelompok B2 di TK Pradnya Paramita. [Singaraja]: Universitas Pendidikan Ganesha; 2013.

9. Chan MF. Factors affecting nursing staff in practising spiritual care. J Clin Nurs [Internet]. 2010 Aug;19(15-16):2128-36. Available from: http://doi. wiley.com/10.1111/j.1365-2702.2008.02690.x

10. Hamid A. Bunga Rampai: Asuhan Keperawatan Kesehatan Jiwa. Jakarta: EGC; 2008.

11. Lynch L, Hancox K, Happel B. Clinical Supervision for Nurses. Wiley-Blackwell; 2008.

12. Wong KF, Lee LYK, Lee JKL. Hong Kong enrolled nurses' perceptions of spirituality and spiritual care. Int Nurs Rev [Internet]. 2008 Sep;55(3):333-40. Available from: http://doi.wiley. com/10.1111/j.1466-7657.2008.00619.x

13. Puguh W, Rr Tutik SH, Hanny H. Pengaruh Pelatihan Supervisi terhadap Penerapan Supervisi Klinik Kepala Ruang dan Peningkatan Kualitas Tindakan Perawatan Luka Di RS PKU Muhammadiyah Temanggung. Pros Konf Nas PPNI Jawa Teng [Internet]. 2013 [cited 2017 Sep 20];44-51. Available from: http://jurnal. unimus.ac.id/index.php/psn12012010/article/ viewFile/848/902

14. Susilowati E, Santoso S, Hamidi N. Penggunaan Metode Pembelajaran Drill sebagai Upaya Meningkatkan Prestasi Belajar Akuntansi. Jupe UNS [Internet]. 2013 [cited 2017 Sep 20];1(3):110. Available from: https://media.neliti.com/media/ publications/13548-ID-pengunaan-metodepembelajaran-drill-sebagai-upaya-meningkatkanprestasi-belajar.pdf 